\title{
Streptococcus dentapri sp. nov., isolated from the wild boar oral cavity
}

\author{
Kazuko Takada, ${ }^{1}$ Kazuhiko Hayashi, ${ }^{2}$ Yutaka Sato ${ }^{3}$ \\ and Masatomo Hirasawa ${ }^{1}$
}

Correspondence
Kazuko Takada
takada.kazuko@nihon-u.ac.jp

\author{
${ }^{1}$ Department of Microbiology and Immunology, Nihon University School of Dentistry at Matsudo, \\ Matsudo, Chiba 271-8587, Japan \\ ${ }^{2}$ Department of Oral Medicine, Nihon University School of Dentistry at Matsudo, Matsudo, Chiba \\ 271-8587, Japan \\ ${ }^{3}$ Department of Biochemistry, Tokyo Dental College, Mihama, Chiba 261-8502, Japan
}

Oral streptococci make up a proportion of the normal flora of the oral cavity in humans and animals. Among oral streptococci, the mutans group is one of the groups of micro-organisms responsible for dental caries (Hamada \& Slade, 1980; Loesche, 1986). This group was proposed because its members share similar phenotypic characteristics. One of the causes of caries is an enzyme, glucosyltransferase (GTase), which is produced by this group of bacteria. GTase catalyses the formation of sticky water-insoluble glucans from sucrose. The glucans adhere oral bacteria to teeth and so lead to the formation of dental plaque. The bacteria continue to produce acid on the tooth surfaces and cause dental caries (Hamada \& Slade, 1980; Loesche, 1986). Previously, we reported a novel mutans streptococci, Streptococcus orisuis, isolated from the oral cavity of a pig (Takada \& Hirasawa, 2007). GTase gene $(g t f)$ studies and rat caries experiments involving $S$. orisuis have been performed (ShinozakiKuwahara et al., 2008; Yamaguchi, 2008). Streptococcus dentirousetti (Takada \& Hirasawa, 2008), isolated from the bat oral cavity, showed a $g t f$ gene sequence similar to that

Abbreviation: GTase, glucosyltransferase.

The GenBank/EMBL/DDBJ accession number for the 16S rRNA gene sequence of strain NUM $1529^{\top}$ is AB469560.

DNA-DNA hybridization values for strain NUM $1529^{\top}$ and related streptococci are available as supplementary material with the online version of this paper. of S. orisuis (unpublished GenBank accession no. AB355819). The colonization of the oral cavity by mutans streptococci is assumed to result from sucrose intake. As wild boars are omnivorous animals, they will probably have the opportunity to ingest sucrose. We investigated the microflora of the oral cavities of wild boars, focusing on mutans streptococci.

To investigate the oral microflora of wild boars, mitis salivarius agar (MS agar; Difco) and MS agar supplemented with $0.2 \mathrm{U}_{\text {bacitracin }} \mathrm{ml}^{-1}$ (MSB agar) are widely used to isolate Streptococcus mutans as well as other oral streptococcal species. The four mutans streptococcus-like strains on MSB agar selected for this study were chosen randomly from 38 isolates of streptococci obtained from the oral cavities of eight generally healthy wild boars (three from Aomori and five from Tokushima prefectures in Japan). The strains were grown on brain heart infusion (BHI; Difco) agar supplemented with $5 \%$ horse blood at $37{ }^{\circ} \mathrm{C}$ in an atmosphere of $95 \% \mathrm{~N}_{2}$ and $5 \% \mathrm{CO}_{2}$. Biochemical analysis was conducted using the Rapid ID32 Strep, API 50CH and API ZYM systems (bioMérieux) according to the manufacturer's instructions.

The colony-forming and biochemical characteristics resembled those of the mutans streptococci group. The four strains (NUM $1529^{\mathrm{T}}$ and NUM 1530-NUM 1532) formed small, raised adherent colonies with irregular margins and dark-blue colour on MS agar plates after $48 \mathrm{~h}$ at $37^{\circ} \mathrm{C}$. 
Mutans streptococci usually form small, raised, rough, paleblue colonies on MS agar, which contains $5 \%$ sucrose. The unique colonial morphology of mutans streptococci is due to the production of insoluble glucans from sucrose (Hamada \& Slade, 1980). Colonies of the isolates grown on MS agar were similar in morphology to those of mutans-like streptococci. A water-insoluble material was produced following incubation with sucrose, and the culture supernatant was analysed by colorimetric assay (Van Handel, 1967; Fukushima et al., 1981). An adhesive, water-insoluble glucan was synthesized from sucrose by GTase, which was produced by strain NUM $1529^{\mathrm{T}}$.

DNA was extracted from bacterial cultures using the Wizard Genomic DNA purification kit (Promega) according to the manufacturer's instructions. The $\mathrm{G}+\mathrm{C}$ content of the DNA was determined by HPLC using a method described previously (Hirasawa \& Takada, 1994). The G + C content of strains NUM $1529^{\mathrm{T}}$ and NUM 1530 NUM 1532 ranged from 39 to $41 \mathrm{~mol} \%$. To determine the phylogenetic affinity of each of the isolates, almost the entire 16S rRNA gene of each strain was sequenced and subjected to a comparative analysis, as described previously (Takada \& Hirasawa, 2008). Previously determined 16S rRNA gene sequences used for comparisons in this study were retrieved from the DDBJ, EMBL and GenBank nucleotide sequence databases. Sequence data were aligned with CLUSTAL W (Thompson et al., 1994) and the alignment was corrected by manual inspection. Nucleotide substitution rates ( $K_{\text {nuc }}$ values) were calculated (Kimura, 1980) after gaps and unknown bases were eliminated. The phylogenetic tree was constructed by employing the neighbour-joining method (Saitou \& Nei, 1987).
Bootstrap resampling analysis (Felsenstein, 1985) was performed to estimate the reliability of the topologies. Strain NUM $1529^{\mathrm{T}}$ exhibited high $16 \mathrm{~S}$ rRNA gene sequence similarities with members of the pyogenic group (S. equi subsp. equi ATCC $33398^{\mathrm{T}}, 94.7 \%$; S. equi subsp. zooepidemicus ATCC $43072^{\mathrm{T}}, 94.0 \%$ ) and the mutans group ( $S$. orisuis NUM $1001^{\mathrm{T}}$, $94.1 \%$; S. ferus ATCC $33477^{\mathrm{T}}$, $93.9 \%$; S. ratti ATCC $19645^{\mathrm{T}}, 93.7 \%$; S. macacae ATCC $35911^{\mathrm{T}}$, $92.9 \%)$. A neighbour-joining tree depicting the phylogenetic position of strain NUM $1529^{\mathrm{T}}$ within the genus Streptococcus is shown in Fig. 1. The topology of this phylogenetic tree, together with comparative $16 \mathrm{~S}$ rRNA gene sequence analysis, gave divergence values of $<7 \%$ between the novel isolate and its nearest recognized relatives and mutans streptococci group. The results of phylogenetic analysis show strain NUM $1529^{\mathrm{T}}$ grouping with many of the organisms considered members of the mutans group (Fig. 1).

DNA-DNA hybridization was performed according to the microtitre plate method (Ezaki et al., 1989) with minor modifications (Takada \& Hirasawa, 2007). DNA-DNA relatedness was examined using labelled DNA from strain NUM $1529^{\mathrm{T}}$ with related type strains (Supplementary Table S1, available in IJSEM Online). There were very high levels of relatedness among the four isolated strains, confirming a relationship at the species level. DNA-DNA relatedness values between strain NUM $1529^{\mathrm{T}}$ and closely related type strains of Streptococcus species showed low levels of relatedness (less than 12\%).

Mutans streptococci have eight different serotypes, $a-h$, based on the cell-surface carbohydrate antigens (Hamada

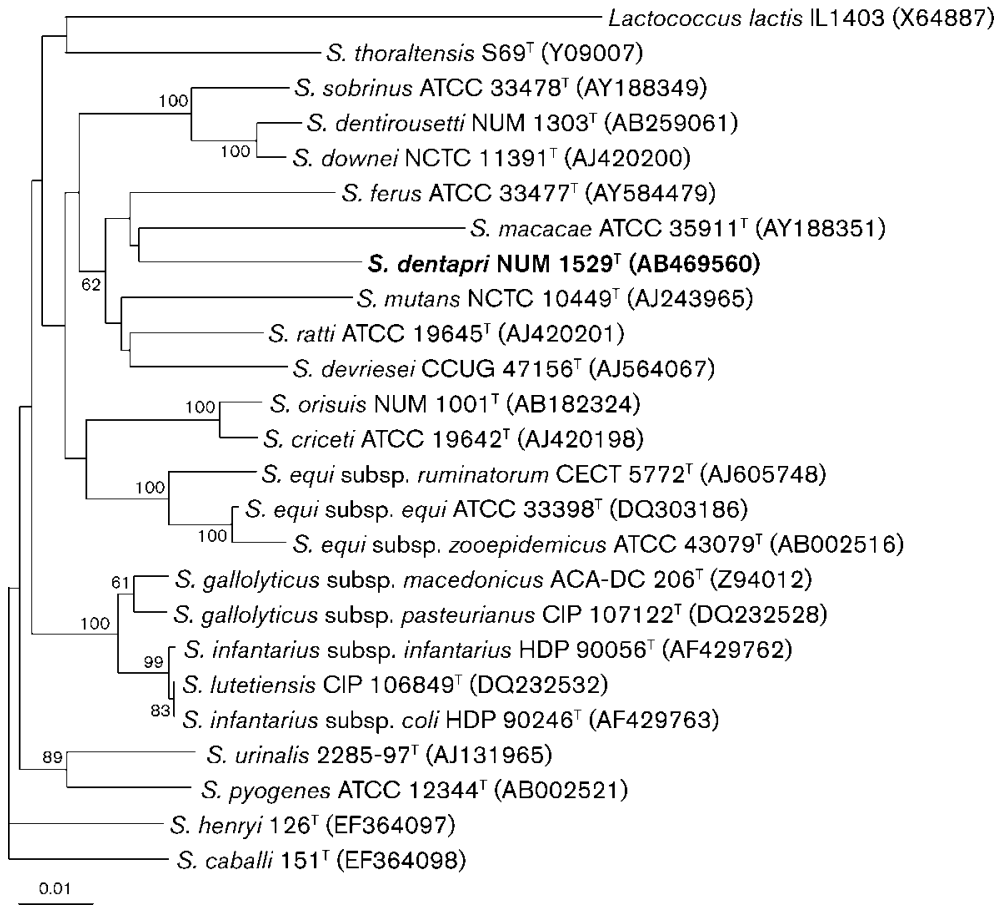

Fig. 1. Phylogenetic tree showing the positions of strain NUM $1529^{\top}$ and related members of the genus Streptococcus, based on 16S rRNA gene sequences and constructed with the neighbour-joining method. Bootstrap percentages ( $>50 \%$ ) based on 1000 resamplings are shown at branch nodes. Bar, 0.01 substitutions per nucleotide position. 
\& Slade, 1980; Whiley \& Beighton, 1998). Two more serotypes, $k$ and $p$, have recently been proposed (Nakano et al., 2004; Takada et al., 2008). The serotype of strain NUM $1529^{\mathrm{T}}$ was determined with an agar-gel immunodiffusion test using rabbit antisera raised against reference strains, prepared as described previously (Hirasawa et al., 1980; Takada et al., 1984). Rantz-Randall-extract antigens (Rantz \& Randall, 1955) were prepared from cells of overnight BHI cultures. Immunodiffusion experiments with strain NUM $1529^{\mathrm{T}}$ identified only the serotype $c$ antibody. No cross-reactive precipitin bands were formed with sera prepared against other serotypes. These results suggest that the novel isolate NUM $1529^{\mathrm{T}}$ should be grouped in serotype $c$. The presence of Lancefield carbohydrate antigens was also tested (streptococcal grouping kit; Oxoid), and none were detected.

The phenotypic characteristics that differentiate the proposed species from closely related species are shown in Table 1. Based on the distinct phenotypic and genotypic characteristics and the phylogenetic evidence, we believe that the four isolates warrant classification in a novel species of the genus Streptococcus, as a member of the mutans streptococci, for which the name Streptococcus dentapri sp. nov. is proposed.

\section{Description of Streptococcus dentapri sp. nov.}

Streptococcus dentapri (den.tap'ri. L. n. dens, -tis tooth; L. masc. n. aper, apri wild boar; N.L. gen. n. dentapri from the tooth of a wild boar).

Table 1. Characteristics differentiating strain NUM $1529^{\top}$ from closely related species of the genus Streptococcus

Taxa: 1, Streptococcus dentapri sp. nov. NUM $1529^{\mathrm{T}} ; 2$, S. equi subsp. equi DSM $20561^{\mathrm{T}} ; 3$, S. equi subsp. zooepidemicus DSM $20727^{\mathrm{T}} ; 4, \mathrm{~S}$. orisuis NUM $1001^{\mathrm{T}}$; 5, S. ferus; 6, S. ratti; 7, S. macacae. Data in columns 1-4 were obtained in this study; data in columns 5-7 were taken from Whiley \& Beighton (1998). NA, Not applicable.

\begin{tabular}{|lccccccc|}
\hline Characteristic & $\mathbf{1}$ & $\mathbf{2}$ & $\mathbf{3}$ & $\mathbf{4}$ & $\mathbf{5}$ & $\mathbf{6}$ & $\mathbf{7}$ \\
\hline Fermentation of: & & & & & & & \\
$\quad$ Lactose & - & - & + & + & + & + & + \\
Mannitol & + & - & - & + & + & + & + \\
Melibiose & - & - & - & + & - & + & - \\
Raffinose & - & - & - & + & - & + & + \\
Sorbitol & + & - & + & + & + & + & + \\
Trehalose & + & - & - & + & + & + & + \\
Hydrolysis of: & & & & & & & \\
$\quad$ Aesculin & + & - & - & + & - & + & - \\
$\quad$ Arginine & - & + & + & - & - & + & - \\
Voges-Proskauer & + & - & - & + & + & + & + \\
test & & & & & & & \\
Lancefield antigen & None & C & C & None & None & None None \\
Serovar of mutans & $c$ & NA & NA & $d$ & $c$ & $b$ & $c$ \\
group & & & & & & & \\
\hline
\end{tabular}

Cells are Gram-stain-positive, non-spore-forming cocci occurring in pairs or short chains. Colonies on blood agar are small and white, $0.75-1.0 \mathrm{~mm}$ in diameter and nonhaemolytic at $37{ }^{\circ} \mathrm{C}$ for $24 \mathrm{~h}$. The cells form small, darkblue, crinkled colonies on MS agar. Facultatively anaerobic and catalase-negative. No Lancefield carbohydrate antigens are detected. With Rapid ID32 Strep and API 50CH, produces acid from glucose, fructose, D-mannose, Dmannitol, D-sorbitol, $\mathrm{N}$-acetylglucosamine, amygdalin, arbutin, aesculin, salicin, cellobiose, maltose, sucrose and trehalose, but not from galactose, lactose, D-ribose, raffinose, melibiose or tagatose. With Rapid ID32 Strep and API ZYM, alanine-phenylalanine-proline arylamidase, $\alpha$ - and $\beta$-glucosidases, acid and alkaline phosphatases, leucine, valine and cystine arylamidases and naphthol-ASBI-phosphohydrolase are produced. Arginine dihydrolase, $\beta$-glucuronidase, $\alpha$ - and $\beta$-galactosidases and $N$-acetyl- $\beta$ glucosaminidase are not produced. Voges-Proskauer test is positive. Hippurate hydrolysis test is negative. Not susceptible to bacitracin. A water-insoluble glucan is produced by glucosyltransferase from sucrose. The serotype is type $c$. The DNA G $+\mathrm{C}$ content of the type strain is $39.9 \mathrm{~mol} \%$.

The type strain is NUM $1529^{\mathrm{T}}\left(=\mathrm{JCM} 15752^{\mathrm{T}}=\mathrm{DSM}\right.$ $21999^{\mathrm{T}}$ ), isolated from the oral cavity of a wild boar.

\section{Acknowledgements}

We are grateful to Dr Jean Euzéby for suggesting the species name. This study was supported in part by a Grant-in-Aid for SPSR from MECSST 2008-12.

\section{References}

Ezaki, T., Hashimoto, Y. \& Yabuuchi, E. (1989). Fluorometric deoxyribonucleic acid-deoxyribonucleic acid hybridization in microdilution wells as an alternative to membrane filter hybridization in which radioisotopes are used to determine genetic relatedness among bacterial strains. Int J Syst Bacteriol 39, 224-229.

Felsenstein, J. (1985). Confidence limits of phylogenies: an approach using the bootstrap. Evolution 39, 783-791.

Fukushima, K., Motoda, R. \& Ikeda, T. (1981). Effects of exogenous insoluble glucan primer on insoluble glucan synthesis by Streptococcus mutans. J Dent Res 60, 1707-1712.

Hamada, S. \& Slade, H. D. (1980). Biology, immunology, and cariogenicity of Streptococcus mutans. Microbiol Rev 44, 331-384.

Hirasawa, M. \& Takada, K. (1994). Porphyromonas gingivicanis sp. nov. and Porphyromonas crevioricanis sp. nov., isolated from beagles. Int J Syst Bacteriol 44, 637-640.

Hirasawa, M., Kiyono, H., Shiota, T., Michalek, S. M. \& McGhee, J. R. (1980). Virulence of Streptococcus mutans: immunochemical characterization of a serotype $g$-defective mutant (C307). Infect Immun 27, 697-699.

Kimura, M. (1980). A simple method for estimating evolutionary rates of base substitutions through comparative studies of nucleotide sequences. J Mol Evol 16, 111-120.

Loesche, W. J. (1986). Role of Streptococcus mutans in human dental decay. Microbiol Rev 50, 353-380. 
Nakano, K., Nomura, R., Nakagawa, I., Hamada, S. \& Ooshima, T. (2004). Demonstration of Streptococcus mutans with a cell wall polysaccharide specific to a new serotype, $k$, in the human oral cavity. J Clin Microbiol 42, 198-202.

Rantz, L. A. \& Randall, E. (1955). Use of autoclaved extracts of hemolytic streptococci for serological grouping. Stanford Med Bull 13, 290-291.

Saitou, N. \& Nei, M. (1987). The neighbor-joining method: a new method for reconstructing phylogenetic trees. Mol Biol Evol 4, 406425.

Shinozaki-Kuwahara, N., Takada, K. \& Hirasawa, M. (2008). Sequence and phylogenetic analyses of novel glucosyltransferase gene of mutans streptococci isolated from pig oral cavity. J Microbiol 46, 202-208.

Takada, K. \& Hirasawa, M. (2007). Streptococcus orisuis sp. nov., isolated from the pig oral cavity. Int J Syst Evol Microbiol 57, 1272-1275.

Takada, K. \& Hirasawa, M. (2008). Streptococcus dentirousetti sp. nov., isolated from the oral cavity of bats. Int J Syst Evol Microbiol 58, 160163.
Takada, K., Wyszomirska, J. \& Shiota, T. (1984). Serological characterization of Streptococcus mutans serotype polysaccharide $g$ and its different molecular weight forms. Infect Immun 45, 464469.

Takada, K., Igarashi, M., Yamaguchi, Y. \& Hirasawa, M. (2008). New serotype of mutans streptococci isolated from pig oral cavity. Microbiol Immunol 52, 64-68.

Thompson, J. D., Higgins, D. G. \& Gibson, T. J. (1994). CLUSTAL W: improving the sensitivity of progressive multiple sequence alignment through sequence weighting, position-specific gap penalties and weight matrix choice. Nucleic Acids Res 22, 46734680.

Van Handel, E. (1967). Determination of fructose and fructoseyielding carbohydrates with cold anthrone. Anal Biochem 19, 193194.

Whiley, R. A. \& Beighton, D. (1998). Current classification of the oral streptococci. Oral Microbiol Immunol 13, 195-216.

Yamaguchi, Y. (2008). Cariogenicity of three kinds of mutans streptococci from pig oral cavity. Int J Oral Med Sci 7, 67-71. 